University of South Florida

DIGITAL COMMONS

Digital Commons @ University of

@ UNIVERSITY OF SOUTH FLORIDA

South Florida

School of Geosciences Faculty and Staff

Publications

School of Geosciences

4-1986

\title{
Determination of Large-Scale Velocity Structure of the Crust and Upper Mantle in the Vicinity of Pavlof Volcano, Alaska
}

Stephen R. McNutt

Columbia University, smcnutt@usf.edu

K. H. Jacob

Follow this and additional works at: https://digitalcommons.usf.edu/geo_facpub

Part of the Earth Sciences Commons

\section{Scholar Commons Citation}

McNutt, Stephen R. and Jacob, K. H., "Determination of Large-Scale Velocity Structure of the Crust and Upper Mantle in the Vicinity of Pavlof Volcano, Alaska" (1986). School of Geosciences Faculty and Staff Publications. 254.

https://digitalcommons.usf.edu/geo_facpub/254

This Article is brought to you for free and open access by the School of Geosciences at Digital Commons @ University of South Florida. It has been accepted for inclusion in School of Geosciences Faculty and Staff Publications by an authorized administrator of Digital Commons @ University of South Florida. For more information, please contact digitalcommons@usf.edu. 
JOURNAL OF GEOPHYSICAL RESEARCH, VOL. 91, NO. B5, PAGES 5013-5022, APRIL 10, 1986

DETERMINATION OF LARGE-SCALE VELOCITY STRUCTURE OF THE CRUST AND UPPER MANTLE IN THE VICINITY OF PAVLOF VOLCANO, ALASKA

\author{
S. R. McNutt ${ }^{1}, 2$ and K. H. Jacob
}

Lamont-Doherty Geological Observatory of Columbia University, Palisades, New York

\begin{abstract}
Pavlof Volcano is 2715-m-high atratovolcano located at latitude $55.4^{\circ} \mathrm{N}$ and longitude $161.9^{\circ} \mathrm{W}$, near the western end of the Alaska Peninsula. In this study the large-scale 1 ateral perturbations to a vertical reference velocity structure in the vicinity of Pavlof Volcano are determined using modified versions of standard three-dimensional inversion techniques. We use as the primary data set $P$ wave arrival times and residuals from shallow ( $<40 \mathrm{~km}$ deep) regional earthquakes located by the Shumagin Islands seismic network. Relative residuals mainly from refracted (e.g., Pn) arrivals allow us to constrain models for a laterally varying crustal velocity structure. Several strong ray path dependent pattems are seen in the residuals; the most pronounced is that rays passing through the crust beneath the volcano are delayed (positive residuals) by up to $1.0 \mathrm{~s}$, while those rays traveling subparallel to and behind the volcanic axis on the retroarc (Bering Sea) side arrive as much as $0.5 \mathrm{~s}$ early (negative residuals). The corresponding results of a formal velocity inversion show the presence of a lowvelocity body beneath the volcanic arc that coincides geographically with Emmons Caldera $(10 \mathrm{~km}$ SW of Pavlof). Computed velocity values are about 12-14\% lower than in the surrounding crust and are comparable to values found at other volcanic areas. The exact shape and position of the low-velocity body and its suitability for geothermal power developraent have not yet been sufficiently determined; for such an assessment a much denser station distribution is required.
\end{abstract}

\section{Introduction}

Recently, a number of related techniques based on a method introduced by Aki et al. [1977] have been used to examine the two- and three-dimensional seismic structure of the earth's crust and upper mantle. In the principal method, one uses travel time residuals as data to invert for slowness perturbations in a volume located beneath an array of seismographs. The closely spaced array of seismographs operated by the Hawaiian Voleano Observatory (HVO) hạs allowed several detailed studies of the velocity structure of the geologicaliy complex summit region of Rilauea Volcano. E11sworth [1977] and E1lsworth and Koyanagi

\footnotetext{
${ }^{I}$ Also at Department of Geological Sciences, Columbia University, Palisades, New York.

${ }^{2}$ Now at California Division of Mines and Geology, Sacramento, California.
}

Copyright 1986 by the American Gepphysical Union.

Paper number 5B 5530.

0148-0227/86/005B-5530\$05.00
[1977] modeled the three-dimensional velocity structure of Kilauea on a spatial scale of 7.5 to $15 \mathrm{~km}$ using teleseismic $P$ wave arrival time data. More recently, Thurber [1984] used a modified technique involving simultaneous inversion for earthquake locations and velocity struccure to model the three-dimensional $P$ wave velocity structure of Kilauea on a spatial scale of 3-4 $\mathrm{km}$ using local earthquake data. A review paper by Iyer [1984] discusses 12 additional cases of teleseismic $P$ wave residual studies at volcanoes and two additional cases of local earthquake arrival time studies.

This paper presents results of a determination of the laterally varying $P$ wave velocity structure of the crust and uppermost part of the mantle in the vicinity of Pavlof Volcano. Pavlof is a 2715-m-high stratovolcano located at latitude $161.9^{\circ} \mathrm{W}$, longitude $55.4^{\circ} \mathrm{N}$, at the western end of the Alaska Peninsula (Figure 1). The station distribution and limited number of suitably sized earthquakes prevented us from applying a standard three-dimensional inversion using teleseismic data. The absence of shallow earthquakes ( $<50$ $\mathrm{km}$ deep) at distances less than $30 \mathrm{~km}$ from Pavlof further prevented us from using Thurber's method (which requires seismic sources within the volume subject to the velocity inversion). Instead, we use $P$ wave travel time data from more distant, regional earthquakes to invert for a laterally heterogeneous velocity model of the crust and uppermost parts of the mantle. We do not attempt to refine the vertical variations of a previously determined regional reference model for the velocities in crust and upper mantle of the Aleutians. Rather we assume that the observed travel time anomalies represent only lateral perturbations of the vertical reference velocity structure. The purpose then is to determine the magnitude of these lateral variations. The study uses relative residuals mainly from refracted (e.g., Pn) arrivals from earthquakes at distances of 104 to $547 \mathrm{~km}$. The sources are located on the adjacent shallow portions of the main thrust zone, well above the steeply dipping portions of the Wadati-Benioff zone.

\section{Data and Analysis}

Microearthquake stations of the Shumagin Is lands regional seismic network operating during the study period (1981-1983) are shown in Figures 1 and 2. Each station is equipped with a vertical, short-period ( 1 s natural period) seismometer; data from all the stations are radio telemetered to a central recording site at Sand Point (SAN, Figure 2). In addition, two orthogonal, short-period horizontal seismometers were operated at several gites (see caption of Figure 2) beginning in 1982. Data are recorded on magnetic tape (both analog and digital), and arrival times can be read with a precision of $0.01 \mathrm{~s}$, 


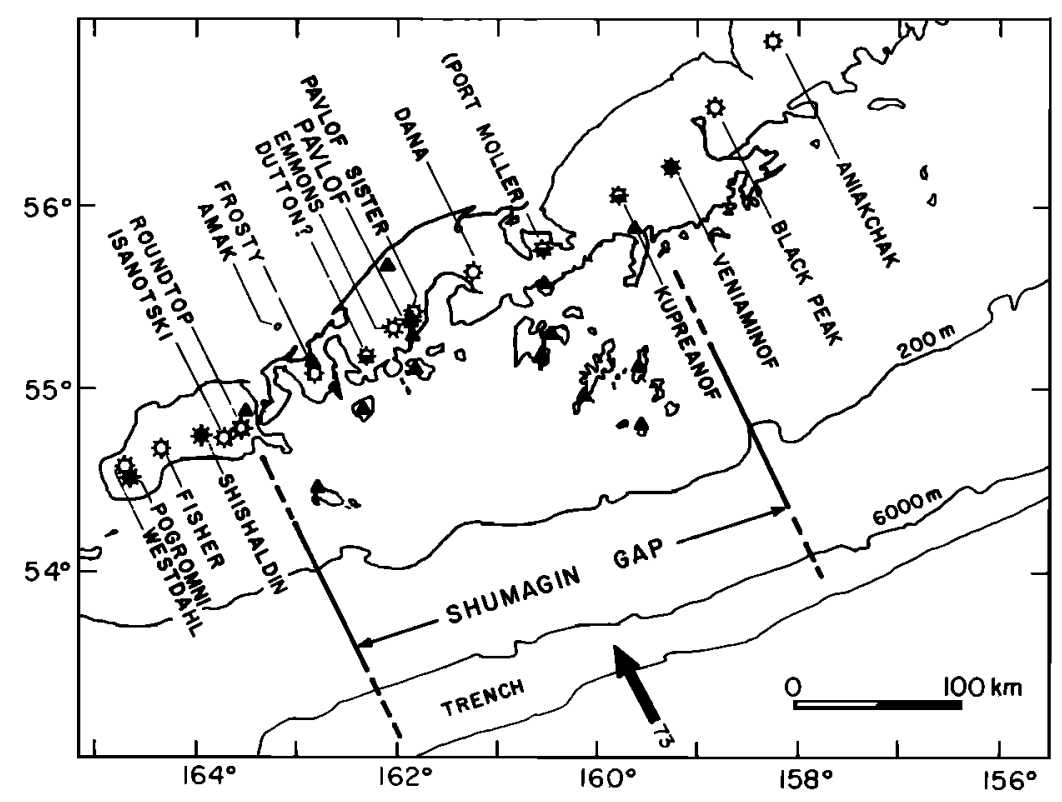

Fig. 1. Index map of the study area. Active (Holocene) volcanoes are shown as star symbols; solid symbols mark volcanoes that have erupted in the past 11 years, while half-solid symbols mark volcanoes that have had activity such as earthquake swarms or geothermal activity. Triangles denote seismic stations. The boundaries of the Shumagin seismic gap are shown as solid lines for the seismogenic portion of the rupture zone and as dashed lines for nonseismogenic portions. The arrow shows the plate convergence rate in $\mathrm{mm} \mathrm{y}^{-1}$ [from Minster and Jordan, 1978].

Figure 2 shows epicenters of the earthquakes used in the velocity inversion; additional parameters of the earthquakes are given in Table 1 . The earthquakes were located using the HYPOINVERSE computer program [Klein, 1978] assuming a horizontally layered model for the central and eastern Aleutian Islands determined from the travel times of central Aleutian nuclear explosions ( $H$. Rowlett and $K$. Jacob, personal communication, 1985). This model represents very well the average $P$ wave velocities of the crust and uppermost mantle directly beneath the Aleutian arc, but it does not account for either volcanic low-velocity bodies or high-velocity slab effects. Figure 3 shows the velocity model at true scale (no vertical exaggeration) as well as a critically refracted ray from the base of the crust to the surface. This ray path is representative of most of the theoretical ray paths from the events used in the inversion. The flat layered earth model is, of course, an approximation of the more complicated three-dimensional true velocity structure. More tectonically realistic cross sections of seismicity, ray paths, and velocity structures associated with a descending slab are given by Reyners and Coles [1982], Hauksson et al. [1984], and Hauksson [1985] for the Shumagins, and by Frohlich et al. [1982] for the central Aleutians. On the other hand, it should be noted that most of the ray paths used in this study do not penetrate sufficiently deep into the mantle to be severely affected by the descending Pacific slab.

The events were selected based on several criteria: good azimuthal distribution, shallow depths, low rms residuals, magnitude, arrivals recorded by at least 12 stations, and reliable arrivals on station BLH. Inversion studies re- quire that a given volume be sampled with a variety of ray paths from different azimuths. Selecting events occurring at on ly shallow depths ensures that most of the ray paths are critically refracted and that any residual patterns are largely independent of source depth. Low rms residuals (a1l $<0.50 \mathrm{~s}$, most $<0.30 \mathrm{~s}$ ) are diagnostic of the better hypocentral solutions. However, individual station residuals may still be large (up to $1.0 \mathrm{~s}$ ). Most events with the larger magnitudes $\left(m_{b}=2.5\right.$ to 6.0 ) have distinct arrivals, which can therefore be read with high precision. These larger events are also usually recorded on all stations, thus reducing relative location errors (which may depend on the presence or absence of certain stations). No station corrections are used.

The study region of interest, the volcanic axis, lies between stations PVV and BLH. In order to obtain $P$ wave residuals for rays that traverse the volcanic arc, it is thus essential that the events be recorded on station BLH, the only station more than $20 \mathrm{~km}$ to the $\mathrm{NW}$ of Pavlof (Figure 2). This station has a long telemetry link, including two repeater stations, and is thus vulnerable to failure from severe winter conditions or bear damage. About one-half of the events initially selected according to the above criteria were not used because they were not recorded on station BLH.

Figure 4 shows relative residuals (for several pairs of stations) as a function of the azimuth with respect to the trend of volcanic arc. The residuals are from the HYPOINVERSE solution, which seeks to minimize the total rms residual. Rays that travel subparallel to the volcanic axis (relative azimuths $\left\langle 20^{\circ}\right.$ and $\rangle 160^{\circ}$ ) arrive early at $\mathrm{BLH}$ and late at PV; hence the relative resid- 


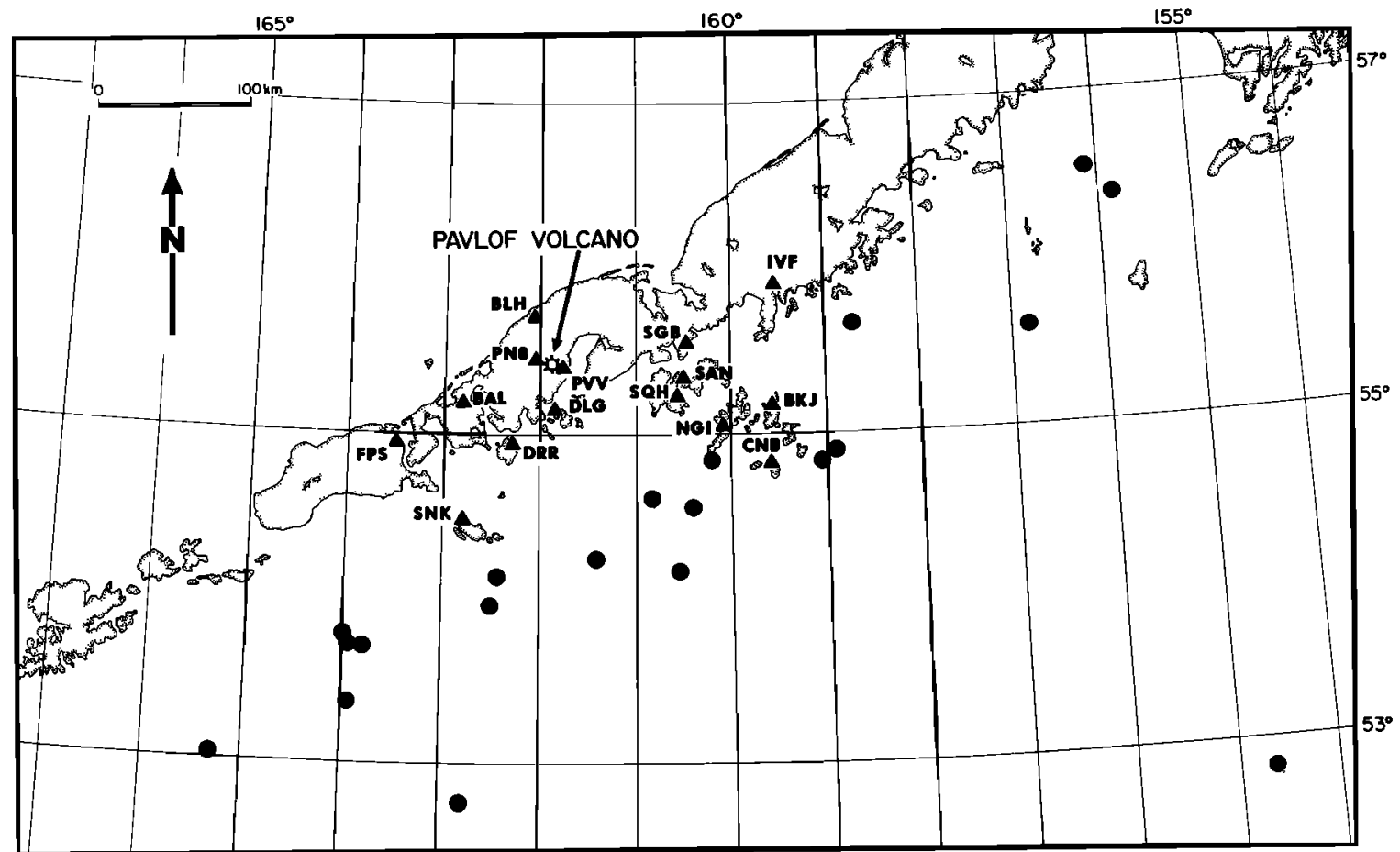

Fig. 2. Seismic stations (triangles) and events (circles) used in the velocity inversion. The nineteen events shown are those whose relative residuals are plotted in Figure 4. Events were located using most of the stations shown. Stations BLH, PVV, CNB, SAN, and SGB were upgraded to three components in 1982.

ual BLH minus PVV is negative (Figure 4a). Rays that $t$ ravel in a direction more perpendicular to the arc (azimuths $60^{\circ}$ to $100^{\circ}$ ) arrive late at BLH and early at PVW; hence the relative residual is positive. Rays at intermediate azimuths have intermediate residual values (near zero). This overall relative residual pattern, which forms the " $U$ " shape in Figure $4 a$, is the most important observation of this study and provides the motivation to attempt a formal inversion for lateral velocity changes.

We computed relative residuals for other sta$t$ ion pairs, such as SGB minus NGI (Figure 4b). These two stations share a similar orientation and separation distance with stations BLH and PVV; they are, however, both located in the fore-

TABLE 1. Parameters of Earthquakes Used in Study

\begin{tabular}{|c|c|c|c|c|c|c|c|c|c|}
\hline & \multicolumn{3}{|c|}{ Origin Time } & \multirow{2}{*}{$\begin{array}{c}\text { Lat., } \\
{ }^{\circ} \mathrm{N}\end{array}$} & \multirow{2}{*}{$\begin{array}{c}\text { Long., } \\
{ }^{\circ} \mathrm{W}\end{array}$} & \multirow{2}{*}{$\begin{array}{c}\text { Depth } \\
\text { km }\end{array}$} & \multirow{2}{*}{$\begin{array}{c}\text { Mag- } \\
\text { nitude }\end{array}$} & \multirow{2}{*}{$\begin{array}{c}\text { RMS } \\
s \\
\end{array}$} & \multirow{2}{*}{$\begin{array}{l}\text { Number of } \\
\text { Stations }\end{array}$} \\
\hline & Date & & UT & & & & & & \\
\hline Aug. & 16 , & 1981 & $0823: 53.64$ & $52^{\circ} 47^{\prime} 69^{\prime \prime}$ & $162^{\circ} 48^{\prime} 93$ & 09.91 & 3.0 & 0.28 & 14 \\
\hline Aug. & 18 , & 1981 & $2255: 37.97$ & $55^{\circ} 39^{\prime} 01^{\prime \prime}$ & $158^{\circ} 43^{\prime} 00$ & 39.29 & 3.6 & 0.19 & 15 \\
\hline Sept. & 6 & 1981 & $1320: 19.70$ & $56^{\circ} 32^{\prime} 13^{\prime \prime}$ & $156^{\circ} 08^{\prime} 92$ & 45.00 & 3.8 & 0.27 & 14 \\
\hline Sept. & 17 & 1981 & $0318: 02.23$ & $53^{\circ} 02^{\prime} 52^{\prime \prime}$ & $165^{\circ} 20^{\prime} 27$ & 08.72 & 4.0 & 0.37 & 14 \\
\hline Sept. & 26 & 1981 & $1748: 14.08$ & $54^{\circ} 51^{\prime} 20^{\prime \prime}$ & $160^{\circ} 13^{\prime} 45$ & 35.20 & 2.6 & 0.18 & 15 \\
\hline Oct. & 5 & 1981 & $1132: 41.76$ & $54^{\circ} 16^{\prime} 18^{\prime \prime}$ & $161^{\circ} 26^{\prime} 25$ & 12.85 & 3.3 & 0.22 & 15 \\
\hline Nov. & 11 , & 1981 & $0224: 52.39$ & $54^{\circ} 11^{\prime} 75^{\prime \prime}$ & $160^{\circ} 34^{\prime} 92$ & 15.40 & 2.4 & 0.31 & 15 \\
\hline Nov. & 14, & 1981 & $0919: 57.35$ & $54^{\circ} 08^{\prime} 10^{\prime \prime}$ & $162^{\circ} 27^{\prime} 47$ & 00.74 & 2.7 & 0.30 & 17 \\
\hline Nov. & 18 , & 1981 & $1934: 43.57$ & $53^{\circ} 22^{\prime} 31^{\prime \prime}$ & $163^{\circ} 58^{\prime} 39$ & 29.71 & 3.6 & 0.22 & 16 \\
\hline Nov. & 18, & 1981 & $2008: 38.90$ & $53^{\circ} 43^{\prime} 82^{\prime \prime}$ & $163^{\circ} 46^{\prime} 86$ & 03.30 & 2.9 & 0.18 & 15 \\
\hline Dec. & 9 & 1981 & $1222: 14.26$ & $52^{\circ} 49^{\prime} 55^{\prime \prime}$ & $154^{\circ} 37^{\prime} 04^{\prime}$ & 32.87 & 4.5 & 0.21 & 18 \\
\hline Dec. & 20 , & 1981 & $1000: 14.36$ & $54^{\circ} 33^{\prime} 59^{\prime \prime}$ & $160^{\circ} 24^{\prime} 34$ & 14.64 & 2.9 & 0.32 & 18 \\
\hline Jan. & 4 & 1982 & $0709: 54.38$ & $53^{\circ} 56^{\prime} 94^{\prime \prime}$ & $162^{\circ} 30^{\prime} 23$ & 04.59 & 2.6 & 0.50 & 18 \\
\hline $\mathrm{J}$ an. & 25 , & 1982 & $2339: 17.71$ & $56^{\circ} 23^{\prime} 13^{\prime \prime}$ & $155^{\circ} 51^{\prime} 68$ & 15.17 & 4.0 & 9.47 & 15 \\
\hline Feb. & 5 & 1982 & $0908: 32.51$ & $54^{\circ} 36^{\prime} 27^{\prime \prime}$ & $160^{\circ} 51^{\prime} 93$ & 02.90 & 2.3 & 0.25 & 11 \\
\hline Feb. & 14, & 1983 & $0320: 03.71$ & $54^{\circ} 48^{\prime} 52^{\prime \prime}$ & $159^{\circ} 06^{\prime} 46$ & 16.11 & 5.6 & 0.44 & 13 \\
\hline Feb. & 14, & 1983 & $0810: 02.72$ & $54^{\circ} 51^{\prime} 72^{\prime \prime}$ & $158^{\circ} 52^{\prime} 48$ & 14.02 & 6.0 & 0.34 & 13 \\
\hline Aug. & 23 , & 1983 & $0647: 32.79$ & $54^{\circ} 37^{\prime} 16^{\prime \prime}$ & $156^{\circ} 51^{\prime} 27$ & 15.17 & 2.8 & 0.18 & 12 \\
\hline Dec. & 29 , & 1983 & $1121: 20.15$ & $53^{\circ} 45^{\prime} 89^{\prime \prime}$ & $163^{\circ} 55^{\prime} 23$ & 28.30 & 2.9 & 0.48 & 13 \\
\hline Dec. & 30 , & 1983 & $2239: 43.82$ & $53^{\circ} 47^{\prime} 68^{\prime \prime}$ & $164^{\circ} 00^{\prime} 10$ & 11.40 & 2.8 & 0.48 & 14 \\
\hline
\end{tabular}




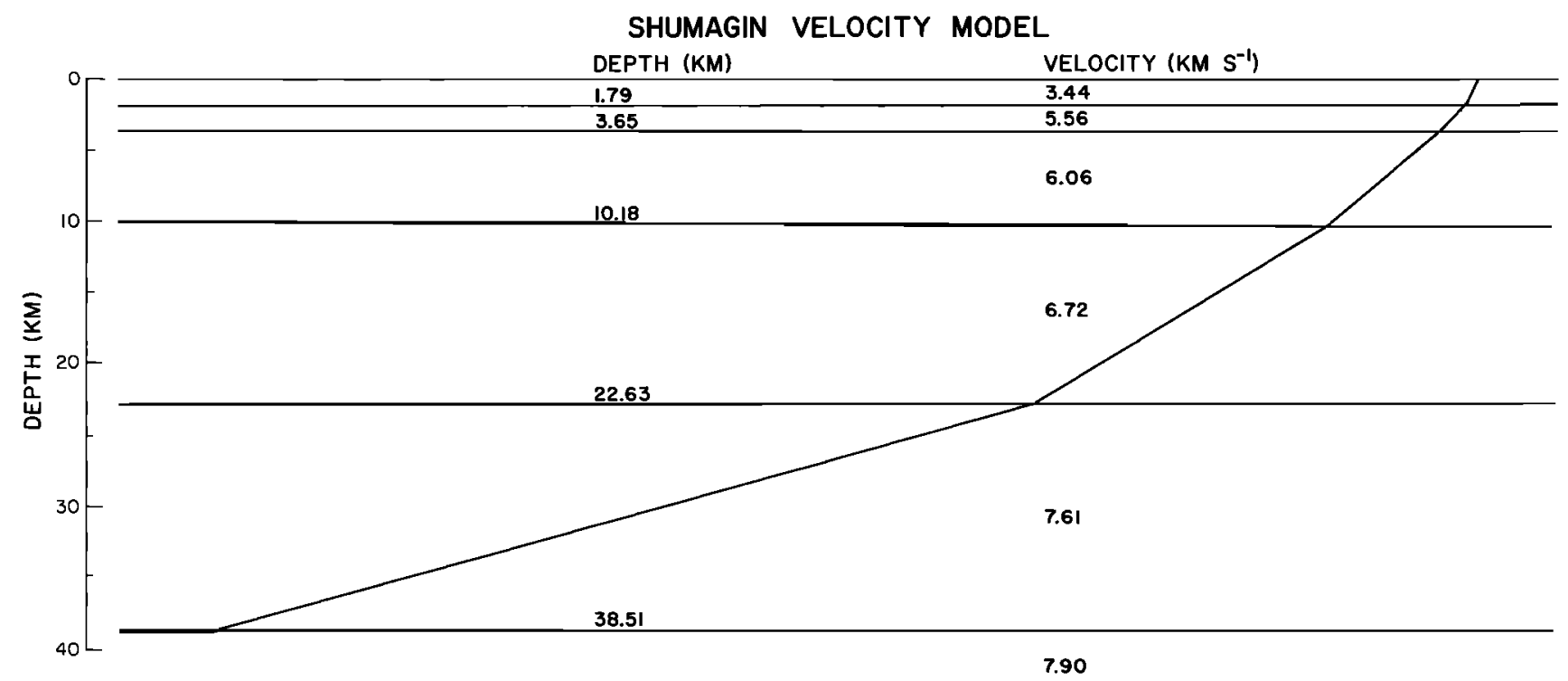

Fig. 3. Velocity structure used for locating earthquakes by the Shumagin Islands seismic network. The horizontal to vertical scale is $1: 1$. Also shown is a critically refracted ray, which is representative of the ray paths taken by most arrivals at stations BLH and PVV.

arc region instead of straddling the volcanic arc. The pattern of relative residuals versus azimuth for stations SGB and NGI (Figure 4b) does not show the "U" shape found in Figure 4a. Relative residuals for station PVV minus station DLG also show no "U" shape pattern. Relative residuals for station BLH minus PN8 show a slight " $U$ " shape, but with larger errors and several exceptions. To summarize, the station pairs entirely south of the volcanic axis (SGB-NGI and PVV-DLG; Figures $4 b$ and $4 c$ ) show no systematic relative residual pattern, while the pair that straddles it (BLH-PVV; Figure 4a) shows a strong, systematic trend. Station pair BLH-PN8 straddles part of the volcanic axis and shows a slight trend (Figure 4d). Thus a strong systematic residual pattern seems related to the volcanic arc only.

Several tests were made to be sure the relative residual pattem of Figure $4 \mathrm{a}$ is real and not an artifact of distance, depth, or systematic mislocations due to network layout. All of the events that fall in azimuths $0-20^{\circ}$ and $160-180^{\circ}$ and that meet the above selection criteria are $>220 \mathrm{~km}$ from Pavlof. We searched the Shumagin earthquake catalog for events at closer distances; we found small shallow events at distances of 73 and $88 \mathrm{~km}$ at azimuths $5^{\circ}$ and $165^{\circ}$, respectively, which have the same residual patterns. Thus we discount distance effects as asignificant cause of the residual pattern of Figure 4a. Depth effects are more problematic. In general, the farther away an event occurs, the less reliable is its computed depth. We examined the hypocentral depths of the events and found that both shallow and deeper events at similar azimuths and distances have similar relative residuals (both positive and negative). Absolute residuals show no systematic azimuth-dependent pattern regardless of the focal depth. We then checked U.S. Geological Survey preliminary determination of epicenters (PDE) solutions. In general, PDE epicentral solutions in the Shumagins are 10-40 km NNW of local network solutions. However, depths are often determined independently from reflected (e.g., pP) arrivals. PDE depths for most of these shallow events agreed with local depth determinations within the uncertainty of measurement.

Moreover, we performed a more general test. We began with the final HYPOINVERSE hypocenter solution, then systematically moved the events 5 $\mathrm{km}$ to the north, south, east, west, deeper, and (where possible) shallower and recalculated the residuals. Relative residuals changed by only a few hundredths of a second in the worst case. Thus we conclude that systematic network misloca$t$ ions alone cannot explain the observed residual patterns.

We next set up the inverse problem to find the velocity perturbations that correspond to the pattern of relative residuals of Figure 4 . We divide the area around the volcano into two different nine-element grids (Figure 5). The first, smaller, grid has equidimensional elements measuring each 17 by $17 \mathrm{~km}$. Al 1 the earthquakes 1 ie outside this grid, and stations BLH and PVV 1 ie inside it. Many rays pass through grid elements $2,5,7,8$, and 9 ; fewer rays pass through elements $1,3,4$, and 6 . The grid orientation and grid spacing are chosen such that one set of grid ines is subparallel to the volcanic axis and that stations BLH and PVV are assigned to separate grid elements. The second grid system is oriented parallel to the first, but this time the elements are larger; in fact, all elements except number 5 are open ended and thus extend out to include all the events. Seven stations, including BLH and PVV, are used with this grid, and the stations are chosen to make the ray path density approximately the same within each grid element. The horizontal path lengths between the earthquakes and stations for each ray through each grid element of both models are computed using a simple ray tracing scheme. The inverse problem 

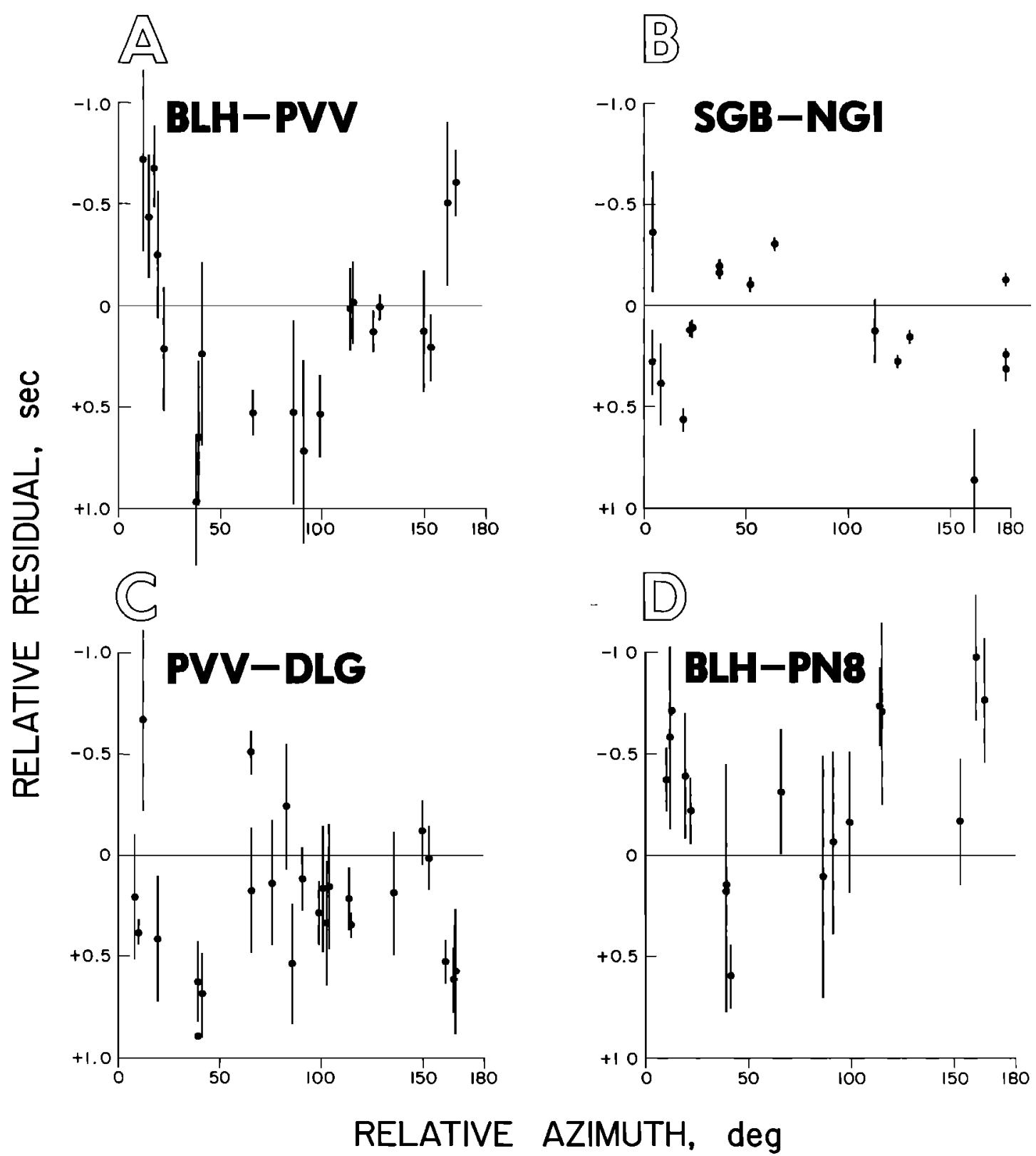

\section{RELATIVE AZIMUTH, deg}

Fig. 4. Relative residuals (residual is observed travel time minus predicted travel $t$ ime) for pairs of stations versus relative azimuth (defined below) from Pavlof Volcano. Negative residuals at any station represent early arrivals, while positive residuals represent late arrivals. The combination of both contribute to the relative residuals plotted. Relative azimuth $0^{\circ}$ is to the WSW of Pavlof along the Alaska Peninsula; $90^{\circ}$ is SSE from the volcano toward the Pacific Ocean, and $180^{\circ}$ is ENE along the Alaska Peninsula. Error bars represent uncertainties in picking the arrival times. (a) Relative residuals for station BLH minus station PVV. (b) Relative residuals for station SGB minus station NGI. (c) Relative residuals for station PV minus station DLG. (d) Relative residuals for station BLH minus station PN8.

is formulated as a linearized approximation whereby we seek the solution to a set of linear equations, one for each residual:

$$
\operatorname{res}_{\mathrm{n}}=\mathrm{d}_{\mathrm{n} 1} s_{1}+\mathrm{d}_{\mathrm{n} 2} s_{2}+\ldots+d_{\mathrm{n} 9} s_{9}
$$

where res $n$ is the residual for the $n^{\text {th }}$ ray, $d_{n 1}$ to $d_{n g}$ are the horizontal distances the $n^{t h}$ ray spends in each grid element, and $s_{1}$ to $s_{g}$ are the (unknown) slowness perturbations (from an average slowness $s_{o}$ ) in the nine gridded regions. The mean of all the residuals is subtracted from each residual. We then have a matrix equation:

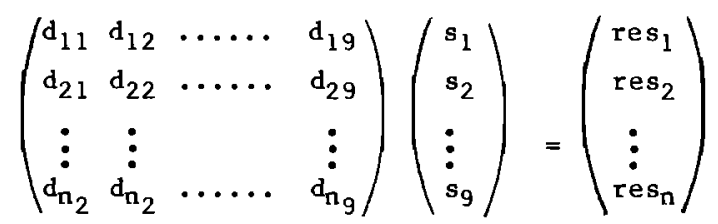



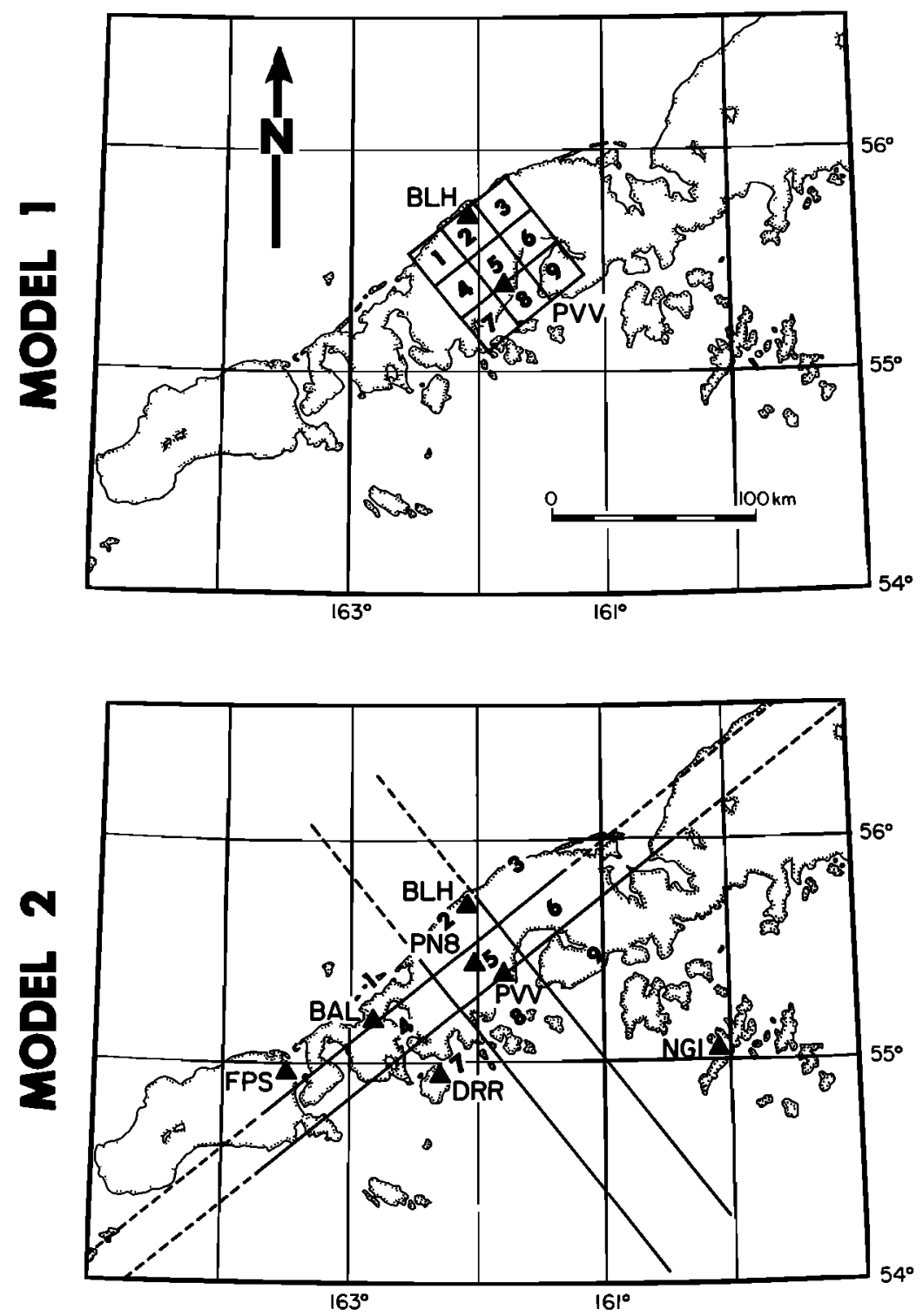

Fig. 5. Grids and stations used for inversion models 1 and 2 . Grid for model 2 is dashed beyond points where rays enter the model. Triangles show station locations.

$$
\text { or } \underline{D} \underline{s}=\underline{r}
$$

$\underline{D}$ and $r$ continually grow in size as more earthquake data are being added. We thus can obtain readily the matrix $\underline{\underline{D}}^{\mathrm{T}} \mathrm{D}$ and vector $\underline{\underline{D}}^{\mathrm{T}}{ }_{\mathrm{I}}$, which are of fixed size (here $9 \times 9$ and $\overline{9} \times 1$, respectively [Thurber, 1981]. $\underline{\underline{D}}^{T}$ is the transposed matrix of $\underline{\underline{D}}$. The next step is the inversion of the matrix equation

$$
\left(\underline{\underline{D}}^{\mathrm{T}} \underline{\underline{D}}\right) \underline{\mathrm{s}}=\underline{\underline{D}}^{\mathrm{T}} \underline{\mathrm{r}}
$$

which is the normal-equations form of (2). Since there are more observations than unknowns, the problem is overdetermined, so we solve it in a least squares sense. The least squares solution

$$
\underline{s}=\left(\underline{D}^{\mathrm{T}} \underline{\mathrm{D}}^{-1} \underline{\mathrm{D}}^{\mathrm{T}} \underline{\mathrm{r}}\right.
$$

tends to be unstable because of random data error [Aki and Lee, 1976]. Therefore we use a damped least squares technique [e.g., Crosson, 1976]. The damped least squares solution is

$$
\underline{\mathbf{s}}=\left(\stackrel{D}{\mathrm{D}}^{\mathrm{T}} \underline{\underline{D}}+\lambda^{2} \stackrel{\mathrm{I}}{=}\right)^{-1} \stackrel{\mathrm{D}^{\mathrm{T}}}{=} \underline{\mathbf{r}}
$$

where $\lambda^{2}$ (units are distance squared) is the damping parameter and $I$ is the identity matrix. In the present case, $\lambda^{=}$can be thought of as a characteristic model length. Adding $\lambda^{2}$ to the diagonal elements of $\underline{\underline{D}}^{\mathrm{T}} \underline{\underline{D}}$ subdues any large changes that would occur for near-zero singular values in the standard least squares inversion [Crosson, 1976]. To test the stability of the solutions, several values for $\lambda^{2}$ were tried. In practice, the undamped least squares solution $\left(\lambda^{2}=0\right)$ is determined first. Then the choice

$$
\lambda^{2}=\frac{\sigma_{i}{ }^{2}}{\sigma_{m}^{2}}
$$




\section{MODEL I}

\begin{tabular}{|c|c|c|}
\hline \multicolumn{3}{|c|}{ UNDAMPED } \\
\hline & 2 & 3 \\
\hline$-14.6 \pm 12.5$ & $3.3 \pm 17.4$ & $-10.8 \pm 6.6$ \\
\hline $7.6 \pm 0.7$ & $6.3 \pm 1.0$ & $7.3 \pm 0.4$ \\
\hline 4 & 5 & 6 \\
\hline $12.8 \pm 13.1$ & B. $1 \pm 15.1$ & $2.9 \pm 6.4$ \\
\hline $5.8 \pm 0.8$ & $6.0 \pm 0.9$ & $6.3 \pm 0.4$ \\
\hline & 8 & 9 \\
\hline$-0.3 \pm 2.9$ & $-1.4 \pm 3.0$ & $-1.3 \pm 4.6$ \\
\hline $6.5 \pm 0.2$ & $6.6 \pm 0.2$ & $6.6 \pm 0.3$ \\
\hline
\end{tabular}

\begin{tabular}{|c|c|c|}
\hline \multicolumn{3}{|c|}{ 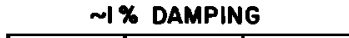 } \\
\hline & 2 & 3 \\
\hline$-8.9 \div 3.7$ & $2.9 \pm 3.7$ & $-5.8 \pm 3.7$ \\
\hline $\begin{array}{c}7.1 \pm 0.2 \\
k m s^{\prime \prime}\end{array}$ & $6.3 \pm 0.2$ & $6.9 \pm 0.2$ \\
\hline & 5 & \\
\hline $8.6 \pm 3.6$ & $4.7 \pm 4.0$ & $1.3 \pm 3.1$ \\
\hline $6.0 \pm 0.2$ & $6.2 \pm 0.3$ & $6.4 \pm 0.2$ \\
\hline 7 & B & \\
\hline$-0.1 \pm 2.8$ & $-0.1 \pm 2.6$ & $-0.4 \pm 3.3$ \\
\hline $6.5 \pm 0.2$ & $6.5 \pm 0.2$ & $6.5 \pm 0.2$ \\
\hline
\end{tabular}

MODEL 2

\begin{tabular}{|c|c|c|}
\hline \multicolumn{3}{|c|}{ UNDAMPED } \\
\hline & 2 & 3 \\
\hline$-23.8 \div 9.9$ & $-2.6 \pm 3.3$ & $-11.3 \pm 8.3$ \\
\hline $\begin{array}{r}8.5 \div 0.6 \\
k_{m}^{\circ} s^{-1}\end{array}$ & $6.7 \pm 0.2$ & $7.3 \pm 0.5$ \\
\hline 4 & 5 & 6 \\
\hline $6.0 \pm 2.0$ & $14.8 \pm 3.0$ & $4.1 \pm 6.6$ \\
\hline $6.1 \pm 0.1$ & $5.7 \pm 0.2$ & $6.2 \div 0.4$ \\
\hline $7^{7}-0.8 \pm 0.3$ & $-0.04 \pm 0.5$ & $-0.1 \pm 0.2$ \\
\hline $6.6 \pm 0.02$ & $6.5 \pm 0.03$ & $6.5 \pm 0.01$ \\
\hline
\end{tabular}

1\% DAMPING
\begin{tabular}{|c|c|c|}
\hline $\begin{array}{r}6.6 \pm 5.0 \\
-6 \%\end{array}$ & $-2.3 \pm 2.7$ & $-4.2 \pm 4.3$ \\
$7.0 \pm 0.3$ & $6.7 \pm 0.2$ & $6.8 \pm 0.3$ \\
$k m s^{-1}$ & 3 & 6 \\
\hline $4.0 \pm 1.7$ & $12.5 \pm 2.6$ & $-0.6 \pm 3.6$ \\
$6.3 \pm 0.1$ & $5.8 \pm 0.2$ & $6.5 \pm 0.2$ \\
\hline $7-0.6 \pm 0.3$ & $0.02 \pm 0.5$ & $-0.04 \pm 0.2$ \\
$6.5 \pm 0.02$ & $6.5 \pm 0.04$ & $6.5 \pm 0.01$ \\
\hline
\end{tabular}

Fig. 6. Block diagrams showing results and errors from the velocity inversion. Results and errors are shown as both slowness perturbations in percent and as resulting velocity values assuming an initial velocity of $6.5 \mathrm{~km} / \mathrm{s}$.

where $\sigma_{i}^{2}$ is the data variance (of the observed residuals) and $\sigma_{m}{ }^{2}$ is the model variance (of the computed slowness perturbations) is utilized; this choice yields a damped least squares solu$t$ ion equivalent to that of the stochastic inverse of Franklin [1970]. Hoerl et al. [1975] have suggested that an appropriate choice for $\lambda^{2}$ is

$$
\lambda^{2}=\frac{{\mathrm{p} \sigma \mathrm{i}^{2}}_{\mathrm{s}}}{\mathrm{s}_{\mathrm{s}}}
$$

where $p$ is the number of grid elements $(=9)$ and $s$ and $s^{T}$ are the solution vector (i.e., resolved perturbations in slowness) and its transpose, respectively. Thus the undamped least squares solution is obtained, $s^{T}$ (scalar product of slowness vectors) is computed, $\lambda^{2}$ determined, and the damped least squares solution obtained. Then $s^{T}$ is recomputed, $\lambda^{2}$ redetermined, etc.; this procedure is carried out iteratively. In our case, $\lambda^{2}$ changed by less than $0.1 \%$ from the first to the second iteration, so we terminated the procedure after two iterations. The "optimized" value of $\lambda^{2}$ in the present case is $1.16 \%$ of the sum of the elements of the leading diagonal of the matrix to be inverted ( $\left.D^{T_{D}}\right)$. This value of $\lambda^{2}$ represents a model length of about $40 \mathrm{~km}$.

\section{Results}

Results of the inversions for both model 1 and model 2 are shown in Figure 6 . The reduction in residual variance is approximately $59 \%$ for model
1 , and $39 \%$ for mode1 2. Results are shown in two ways: as final velocity values computed from an initial velocity of $6.5 \mathrm{~km} \mathrm{~s}^{-1}$ (slowness of 0.154 $\mathrm{s} \mathrm{km}^{-1}$ ), with errors in velocity in $\mathrm{km} \mathrm{s}^{-1}$; and as percent slowness perturbations with errors in percent of initial slowness.

The initial velocity was determined by computing the average velocity of all rays in the model using two methods. First, the straight 1 ine geometric distances for each station/event pair were calculated, and velocities obtained by dividing by travel times. This yields a lower bound for the average crustal velocity of $6.43 \mathrm{~km}$ $\mathrm{s}^{-1}$. Second, the average velocity from the HYPOINVERSE ray tracing subroutine was tabulated. This velocity yields $6.77 \mathrm{~km} \mathrm{~s}^{-1}$. An intermediate velocity rounded off to $6.5 \mathrm{~km} \mathrm{~s}^{-1}$ was eventually used in the presentation of data. Errors are determined by recalculating the residuals through the obtained model and computing standard errors for each grid element.

For each of the two models, we see that grid elements on the retroarc side of the volcanic axis show increased velocities (except for block 2 , model 1), grid elements on the volcanic axis show decreased velocities, and grid elements trenchward of the volcanic axis remain basically unchanged. Grid elements 1, 3, 4, and 6 tend to have relatively larger errors because fewer ray paths cross them. Grid element 2 has a relatively large error because rays from all earthquakes cross it, and residuals at station BLH show large variations (see Figure 4 ). In each case, the damped solutions show smaller perturbations and smaller errors than the undamped solutions (Figure 6).

The largest computed velocity decreases (slowness increases) are about $12-14 \%$ for both models 1 and 2. These are comparable to values found in other volcanic areas, such as $8-15 \%$ in the upper crust at Yellowstone [Iyer et al., 1981a], 10-15\% under Long Valley caldera [Steeples and Iyer, 1976], and 15-30\% beneath Mount Etna [Sharp et al., 1980]. The velocity decreases reported at Mount Etna, and a value of $25 \%$ at the Geysers Clear Lake volcanic field [Iyer et al., 1981b] are the highest values reported in the literature. Iyer [1984] notes that four studies of volcanoes in the Cascades of Oregon and

California have failed to show the presence of significant low-velocity anomalies beneath the volcanoes, so the lowest velocity perturbations in volcanic areas may be not always discernible from the background variations (noise) in the measurements.

The results presented above are subject to certain limitations, some of which are inherent in the particular analysis method. For instance, the method assumes that the shape of heterogeneities is boxlike and the source/receiver configuration imposes a minimum edge length of $17 \mathrm{~km}$ for the boxes. Neither of these configurations has any tectonic rationale. In fact, they may be quite inappropriate to describe the actual structures. Because the actual ray paths are mostly refracted, the rays to station BLH are deeper under blocks 4, 5, and 6 than they are under blocks 1,2 , and 3. A glance at Figures 2 and 3 will confirm this. Blocks 7,8 , and 9 in model 1 are traversed by deep rays (to station BLH) and sha1low rays (to station PVV). The same is true for 


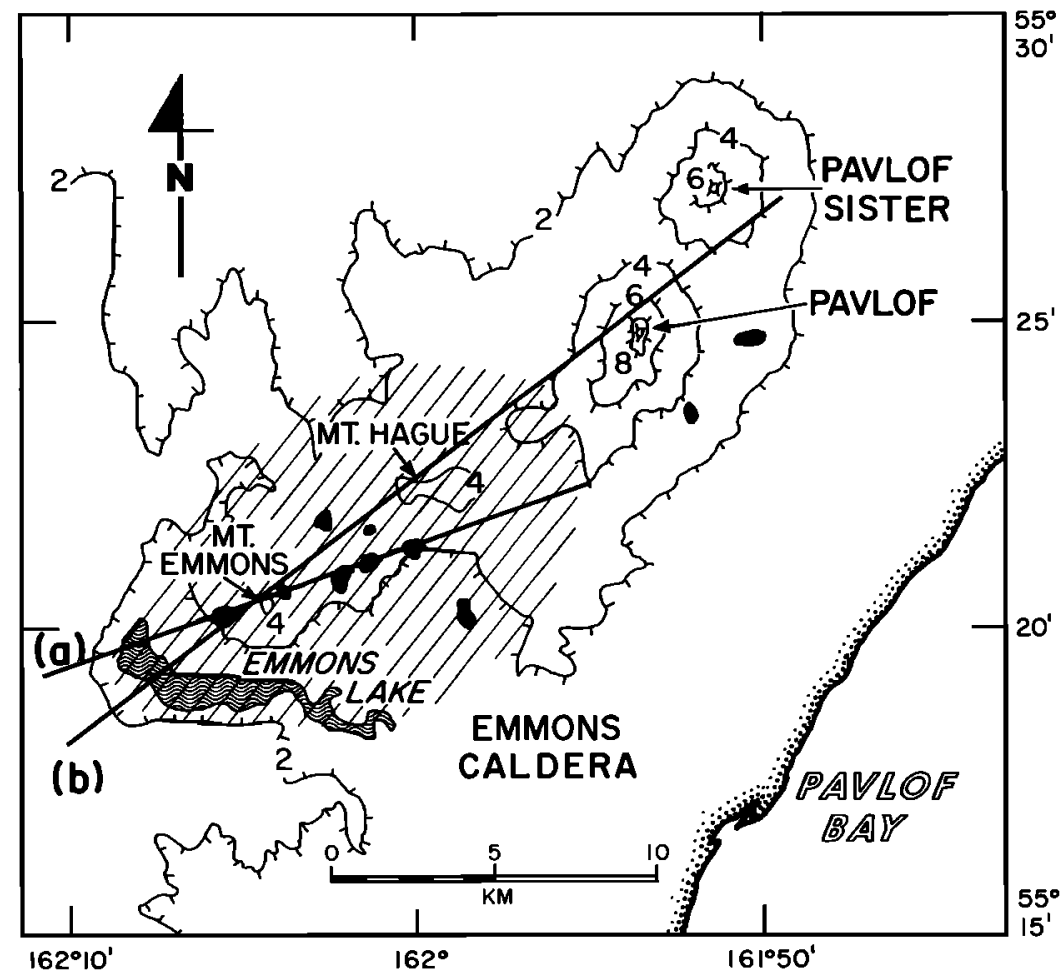

Fig. 7. Simplified geologic map of Pavlof and vicinity on the Alaska Peninsula. Topographic contours are in thousands of feet; tick marks are on the downill side. Irregular small black shapes are cinder cones. The crosshatched area represents the approximate outline of Emmons Caldera as drawn by C. Newhall et al. (written communication, 1984). Heavy shaded lines (a) and (b) indicate two volcanic alignments of probably different origin; line (a) represents an ENE alignment of prominent cinder cones, or other secondary volcanic vents associated probably with a stress-induced fissure. line (b) represents the $\mathrm{NE}$ alignment of the volcanic line ponnecting the primary volcanic structures of Emmons, Hague, Pavlof, and Pavlof Sister and is probably directly related to the strike of the descending slab at depth rather than controlled by the local stress regime. Note the elongation of Emmons Caldera coincides with either direction ( $a$ or $b$ ) equally well.

model 2 , but since here the ray paths in the gridded regions are longer, the average depth is greater. Thus for model 1 the solution for blocks 1, 2, and 3 corresponds to an average depth of $7 \mathrm{~km}$; for blocks 4,5 , and 6 (including the volcanic axis) the average depth is $19 \mathrm{~km}$, and for blocks 7,8 , and 9 the average depth is $12 \mathrm{~km}$. For model 2 the analogous values are 8 , 22 , and $27 \mathrm{~km}$, respectively.

\section{Discussion and Conclusions}

The preferred explanation for the observed low-velocity anomalies is the presence of partial melt in the crust, or some sort of magma chamber. The values for percent of partial melt are commonly thought to be approximately similar to the values for percent velocity decrease, although the unknown geometries of distribution of partial melt (aspect ratios of melt pockets) can lead to large uncertainties [Iyer, 1984]. Blocks 4 and 5 in model 1 correspond in map view with Emmons Caldera and Pavlof, respectively (Figure 7), and block 5 in model 2 includes both blocks 4 and 5 in model 1 . Emmons Caldera is a $10 \times 16 \mathrm{~km}$ depression located about $10 \mathrm{~km}$ SW of Pavlof Volcano (Figure 7). The caldera is the source of ash flows that have traveled at least $50 \mathrm{~km}$ [Miller and Smith, 1975], and calculations based on conductive cooling show that Emmons contains estimated thermal energy of $1.44 \times 10^{21} \mathrm{~J}$ to a depth of $10 \mathrm{~km}$ [Smith and Shaw, 1978]. The out1 ine of Emmons Caldera shown in Figure 7 is drawn strictly based on topography (C. Newhall, personal communication, 1984). Gravity and magnetic data are too sparse in this area to show any anomalies. No electrical resistivity or geodetic surveys have yet been carried out. No local crustal earthquakes have been recorded within 30 $\mathrm{km}$ of Pavlof between 1973 and 1984 [McNutt, 1985; Jacob and Hauksson, 1983], and no refraction surveys have been done. In short, except for topography, no geophysical information existed to confirm the presence or physical gtate of a caldera here until the present study was undertaken. We interpret the low-velocity anomaly in the vicinity of Pavlof Volcano and Emmons Caldera to be a magma chamber at midcrustal depth, i.e., approximately $20 \mathrm{~km}$. Such a chamber could be a distinct feature associated only with Emmons Caldera or a larger zone of magma storage for the whole Emmons Caldera, Pavlof, and Pavlof Sister complex. McNutt and Beavan (in McNutt [1985, Chapter 1]) show that eruptions of Pavlof Volcano 
are periodic; they suggest that nontidal sea level variations may be acting as a trigger mechanism for the eruptions. A magma storage complex at a depth of approximately $20 \mathrm{~km}$ and deeper is consistent with their entirely independent interpret at ion.

The ENE-WSW alignment of cinder cones shown in Figure 7 further suggests that Emmons Caldera, Pavlof, and Pavlof Sister are related, as the cinder cones are all relatively young features. This ENE-WSW alignment of cinder cones (Figure 7 , line a) is perpendicular to the usual alignments of cinder cones at most other volcanoes on the Alaska-Aleutian arc, which are shown by Nakamura et al. [1977] to be perpendicular to maximum horizontal compression, or parallel to the plate convergence vector (Figure 1) between the Pacific and North American plates. Thus the alignment of cinder cones shown in Figure 7 may be the surface expression of a fissure whose orientation is determined by local, rather than regional, stresses. Local stresses may be affected by the continental-to-oceanic crust transition of the overriding North American plate, which occurs in the vicinity of Emmons/Pavlof, and by a zone of anomalous subduction and associated intermediatedepth seismicity adjacent to, and to the east of, Emmons/Pavl of [McNutt, 1985, Chapter 3, Figure $10]$.

The minimum block size in the present study is $17 \mathrm{~km}$. That dimension is the practically achievable resolution of this study. Since seismograms of only local to regional earthquakes are the data, the average frequency content of the $P$ arrivals is between about 5 and $10 \mathrm{~Hz}$. At $6.5 \mathrm{~km}$ $\mathrm{s}^{-1}$, the typical wavelength is then about $1.3 \mathrm{~km}$, and hence the theoretically achievable spatial resolution would be of this order. A distribution of stations (or events!) much denser than the one available for this study would bring the spatial resolution closer to the theoretically achievable one. Because of the finite wavelengths of seismic energy it is likely that dikes, sills, or other similar structures of dimensions less than 1 to 2 km would still not be resolvable.

Other seismologic techniques and data to discern the structure could be explored, as there exist observations to warrant their use. For example, the frequency content of $S$ waves recorded on Pavlof stations for some regional and deep earthquakes is drastically altered. Nearly all the higher frequencies $(>2 \mathrm{~Hz})$ are removed at these stations that lie over the volcanic axis. The same general effect is observed, but to a lesser extent, on seismograms for $P$ waves from both regional events and some teleseisms. Hauksson [1985] shows an example of seismograms from a deep event whose $S$ waves are greatly at tenuated.

In conclusion, the pattern of relative residuals shown in Figure 4 and the results of a two-dimensional velocity inversion support the existence of a low-velocity zone at depth beneath Emmons Caldera and Pavlof Volcano. The lowvelocity zone may be a partial melt in a magma chamber. This study presents the first geophysical evidence to support any physical subsurface expression of Emmons Caldera. Details concerning the three-dimensional shape and extent of the low-velocity zone and its possible suitability for geothermal power development, require the existence of a denser network of seismic stations. Economic development of geothermal power is potentially viable in the Emmons/Pavlov area because of existing and proposed oil exploration efforts in the adjacent Bering Sea lease areas that may require related nearshore and onshore facilities. Other seismologic techniques, such as studies of wave attenuation, can be initiated using available data to verify the existence of an anomalous crustal structure. But both attenuation and velocity resolutions would certainly be improved with at least a temporarily denser network of three component seismic stations than has been available in the past.

Acknowledgements. We thank C. Thurber, J. Mori, T. Boyd, W. Ellsworth, J. Evans, D. Stauber, and G. Zandt for computer programs and helpful comments. The manuscript was critically reviewed by $C$. Scholz and L. Sykes. Suggestions by JGR referees $H$. Iyer, R. Engdahl, and J. Dewey improved the manuscript. R. Bongiorno and A. Dobrovolsky typed the manuscript. This research was supported by the Department of Energy, grant ER-13221. Lamont-Doherty Geological Observatory contribution $\$ 3956$.

\section{References}

Aki, K., and W. H. K. Lee, Determination of three-dimensional velocityanomalies under a seismic array using first $P$ arrival times from local earthquakes, 1 . A homogeneous initial model, J. Geophys. Res., 81, 4381-4399, 1976.

Aki, K., A. Christoffersson, and E. S. Husebye, Determination of the three-dimensional seismic structure of the 1 ithosphere, J. Geophys. Res., 82, 277-296, 1977.

Crosson, R. S., Crustal structure modeling of earthquake data. 1 . Simultaneous least squares estimation of hypocenter and velocity parameters, J. Geophys. Res., 81, 3036-3046, 1976.

Ellsworth, W. L., Three-dimensional structure of the crust and mantlebeneath the Island of Hawaii, Ph.D. thesis, 327 pp., Mass. Inst. of Technol., Cambridge, 1977.

El1sworth, W. L., and R. Y. Koyanagi, Three-dimensional crust and mantlestructure of Kilauea Volcano, Hawai i, J. Geophys. Res., 82, 5379$5394,1977$.

Frankl in, J. N., We11-posed stochastic extensions of il1-posed linear problems. J. Math. Anal. Appl., 31, 682-716, 1970.

Frohlich, C., S. Billington, E. R. Engdahl, and A. Malahoff, Detection and location of earthquakes in the central Aleutian subduction zone using island and ocean bottom seismograph stations, J. Geophys. Res., 87, 6853-6864, 1982.

Hauksson, E., Structure of the Benioff zone beneath the Shumagin Islands, Alaska: Relocation of local earthquakes using three-dimensional ray tracing, J. Geophys. Res., 90, 635-650, 1985.

Hauksson, E., J. Armbruster, and S. Dobbs, Seismicity patterns (1963-1983) as stress indicators in the Shumagin seismic gap, Alaska, Bull. Seismol. Soc. Am., 74, $2541-2558,1984$. 
Hoerl, A. E., R. W. Kennard, and R. F. Baldwin, Ridge regression: Somesimulations. Commun. Stat ist., 4, 105-123, 1975.

Iyer, H. M., Geophysical evidence for the locations, shapes and sizes, and internal structures of magma chambers beneath regions of Quaternary volcanism, Philos. Trans. R. Soc. London, Ser. A, 30, 473-510, 1984.

Iyer, H. M., J. R. Evans, G. Zandt, R. M. St ewart, J. M. Coakley, and J. N. Roloff, A deep low-velocity body under the Yellowstone caldera, Wyoming: Delineation using teleseismic $P$-wave residuals and tectonic interpretations: Summary, Geol. Soc. Am. Bu11., 92, Part I, 792-798, Part II (Microfiche ed.), 1471-1646, 1981a.

Iyer, H. M., D. H. Oppenheimer, T, Hitchcock, J. N. Roloff, and J. M. Coakley, Large teleseismic P-wave delays in the Geysers-Clear Lake geothermal area, Research in the Geysers-Clear Lake Geothermal Area, California, U.S. Geol. Surv. Prof. Pap., 1141, 97-116, $1981 \mathrm{~b}$.

Jacob, K. H., and E. Hauksson, A seismotect onic analysis of the seismic and volcanic hazards in the Pribilof Islands - Eastern Aleutian Islands region of the Bering Sea, final report, contract NOAA 03-5-022-70, 224 pp., Lamont-Doherty Geol. Observ. of Columbia Univ., Palisades, N. Y., 1983.

Klein, F. W., Hypocenter location program HYPOINVERSE, Part 1: Usersguide to versions $1,2,3$, and 4, U.S. Geol. Surv. Open File Rep., 78-694, 64 pp., 1978.

McNutt, s. R., The eruptive activity, seismicity, and velocity structure of Pavlof volcano, eastern Aleutians, Ph.D. thesis, 202 pp., Columbia Univ. New York, 1985.

Miller, T. P., and R. L. Smith, Ash flows on the Alaska Peninsula: A preliminary report on their distribution, composition, and age, Geol. Soc. Am. Abstr. Programs, 7, (7), 1201, 1975.
Minster, J. B., and T. H. Jordan, Present-day plate motions, J. Geophys. Res., 83, 5331$5354,1978$.

Montgomery, D. C., and E. A. Peck, Introduction to Linear Regression analysis, 504 PP., John Wiley, New York, 1981 .

Nakamura, K., K. H. Jacob, and J. N. Davies, Volcanoes as possible indicators of tectonic stress orientation-Aleutians and Alaska, Pure Appl. Geophys., 115, 87-112, 1977.

Reyners, M., and K. S. Coles, Fine structure of the dipping seismic zone and subduction mechanics in the Shumagin Is lands, Alaska, J. Geophys. Res., 87, 356-366, 1982.

Sharp, A. D. L., P. M. Davis, and F. Gray, A low velocity zone beneath Mt. Etna and magma storage, Nature, 287, 587-591, 1980.

Smith, R. L., and H. R. Shaw, Igneous-related geothermal systems, Assessment of Geothermal Resources in the United States-1978, U.S. Geol. Surv. Cir., 790, 12-17, 1978.

Steeples, D. W., and H. M. Iyer, Low-velocity zone under Long Valley as determined from teleseismic events, J. Geophys. Res., 81 , $849-860,1976$.

Thurber, C. H., Earth structure and earthquake locations in the Coyote Lake area, central California, Ph.D. thesis, 332 PD., Mass. Inst. of Technol., Cambridge, 1981.

Thurber, C. H., Seismic detection of the Summit Magma complex of Kilauea Volcano, Hawaii, Science, 223, 165-167, 1984.

S. R. Mcnutt, Department of Conservation, California Division of Mines and Geology, 630 Bercut Drive, Sacramento, CA 95814

K. H. Jacob, Lamont-Doherty Geological

Observatory of Columbia University, Palisades, NY 10964

(Received March 12, 1985; revised December 16, 1985 ; accepted January 3, 1986.) 